\title{
Effects of Operating Conditions on the Flow in the Moving Blade Passage of a Single Stage Axial-Flow Fan
}

\author{
TSUTOMU ADACHI $^{\mathrm{a}, *}$, YUTAKA YAMASHITA $^{\mathrm{b}}$, KENNICHIRO YASUHARA $^{\mathrm{c}}$ and TATSUO KAWAI ${ }^{\mathrm{d}}$ \\ ${ }^{a}$ Faculty of Engineering, Osaka Sangyo University, 3-1-1, Nakagaito, Daito, Osaka, Japan(574); ${ }^{b}$ Hitachi Ltd. Hitachi Works, \\ ${ }^{\mathrm{c}}$ Graduate School, University of Tsukuba, ${ }^{\mathrm{d}}$ Institute of Engineering Mechanics, University of Tsukuba, 1-1-1, Tennodai, \\ Tsukuba, Ibaraki, Japan(305)
}

(Received in final form 24 March 1997)

\begin{abstract}
Three dimensional steady and unsteady velocity distributions in the axial flow fan were measured using a hot wire probe for various operational conditions, various rotational speeds and various measuring positions. For measuring the velocity distributions in the blade passage, a specially designed and manufactured hot wire traversing apparatus was used. Steady velocity distributions, turning angles, effects of incident to the cascade, flow leakage through the tip clearance and effects of the flow separation show the flow phenomena through the blade passages. Unsteady velocity distributions show time dependent procedures of the wake flowing through the moving blade passage. Considering these results of measurements, the effects of the upstream stationary blade and the effects of Reynolds number on the flow were considered.
\end{abstract}

Keywords: Axial flow fan, Flow measurements, Hot wire probe, Three dimensional velocity distributions, Steady and unsteady flow

\section{INTRODUCTION}

In the turbomachinery, there are stationary and moving blade rows making relative movements in the confined area. The flows in these machinery are surrounded by the blade, casing and hub. Along these surfaces there arise boundary layers. Changes of the turning angle inside and outside of the boundary layers accompany secondary flows. If the operational conditions of these machinery are changed, the flow angles are also changed. In the off design conditions, the flow components also cause a radial flow. The viscous wake arising from blade upstream flows in the downstream blade row passages. Flow unsteadiness which is caused by the interaction of the stator wakes with rotor row blades also causes losses. If there is tip clearance between the casing and blade tip, a leakage flow will arise. If the rotational speeds are changed for the same operational conditions, effects of the Reynolds number also accompany a change in flow phenomena.

\footnotetext{
* Corresponding author.
} 
In this paper, three dimensional steady and unsteady flow are measured using a $45^{\circ}$ inclined hot wire probe. Secondary flows accompanying with the change of operational conditions and Reynolds number are shown. Unsteady behaviour arising from the upstream wake are also traced and discussed.

\section{EXPERIMENTAL APPARATUS AND METHOD OF MEASUREMENTS}

\subsection{Experimental Apparatus}

Table I shows the specifications of the single stage axial-flow fan used in this research. It has a comparatively small type number of $k=2.06$. The flow pattern of the fan is a free vortex type. The moving and stationary blades are made of duralmin and machined by numerically controlled milling machine precisely. It can be operated in a wide range of rotational speeds from 300 to $3000 \mathrm{rpm}$. Figure 1 shows variations of the loss $\left(1-\eta_{\max }\right)$ with Reynolds number. The variation

TABLE I Specifications and main dimensions of blower

\begin{tabular}{lc}
\hline Flow coefficient $\Phi$ & 0.507 \\
Pressure coefficient $\Psi$ & 0.550 \\
No. of revolution & $300 \sim 3000 \mathrm{rpm}$ \\
Type number & 2.06 \\
Diameter & $500 \mathrm{~mm}$ \\
Hub ratio & 0.6 \\
No. of stationary blade & 13 \\
No. of moving blade & 10 \\
\hline
\end{tabular}

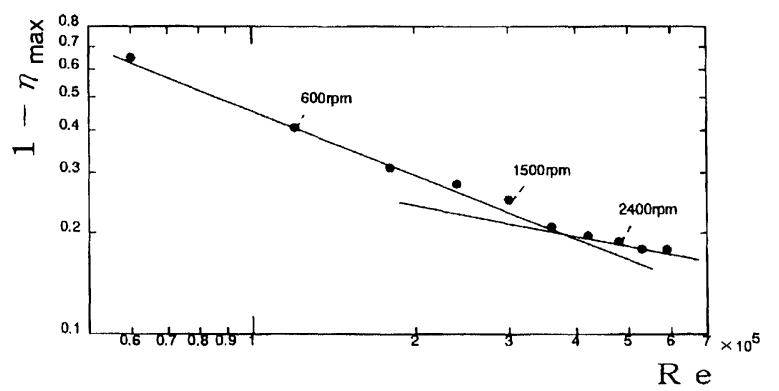

FIGURE 1 Variations of loss $\left(1-\eta_{\max }\right)$ with Reynolds number. can be written as

$$
\left(1-\eta_{\max }\right) \propto \operatorname{Re}^{-m},
$$

where $\eta_{\max }$ denotes the maximum value of efficiency. The value of $m$ is

$$
\begin{array}{lll}
m=0.73 & \text { for } & \operatorname{Re}<3 \times 10^{5}, \\
m=0.3 & \text { for } & \operatorname{Re}>3 \times 10^{5},
\end{array}
$$

where Reynolds number is defined by $\operatorname{Re}=u_{t} \cdot l_{t} / v$ and $u_{t}$ and $l_{t}$ denote velocity and chord length at the blade tip.

\subsection{Traversing Apparatus and Method of Measurements}

Measurements of the three dimensional velocity were carried out in the blade passage and downstream of the moving blade row. For measurements, a hot wire probe with a thickness of $5 \mu \mathrm{m}$ tungsten wire with $45^{\circ}$ inclined to the stem, as shown in Fig. 2, was used. In the measurements, the probe was attached to a probe support in 4 various sorts of positions, one after another. The magnitude of velocity and their directions were calculated from 4 signals taken at the same measuring positions.

In order to traverse the hot wire probe in the circumferential direction during rotation, we used a traversing apparatus as shown in Fig. 3. This apparatus was rotated together with the moving blade row. If we made the stepping motor rotate, then the main body was shifted to a position relative to the shaft. The angle of rotation was $0.135^{\circ}$ per one step of the stepping motor. The radial position of the probe was adjusted in the
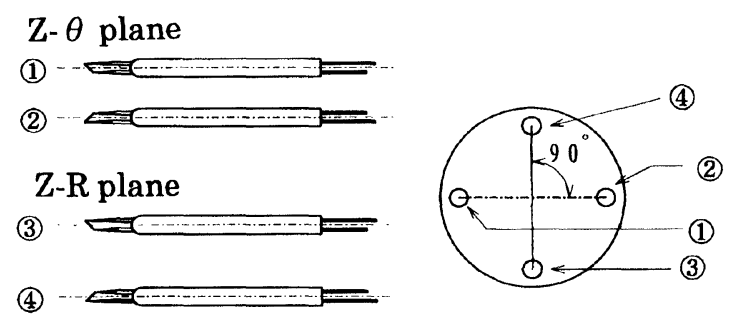

FIGURE 2 Hot wire probe. 
static state. The feed current to the stepping motor and the output signals from the hot wire were sent through the slip-ring attached at one end of the shaft. Measurements of the velocity distributions were taken at various positions in the moving blade row under three operating conditions, i.e., the maximum discharge (FP1), the design point (FP2) and the maximum pressure point (FP3), as shown in Fig. 4. The rotational speeds were 600, 1500 and

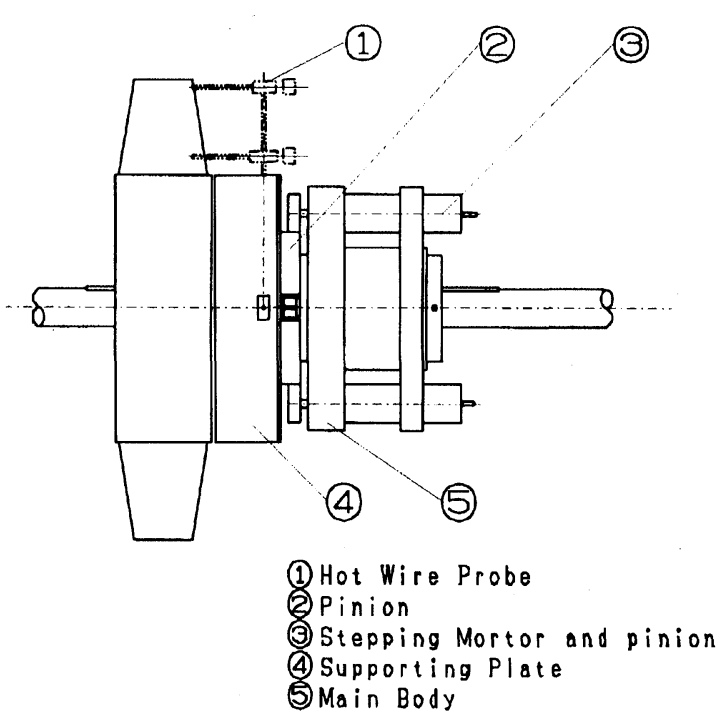

FIGURE 3 Traversing apparatus of the hot wire probe.

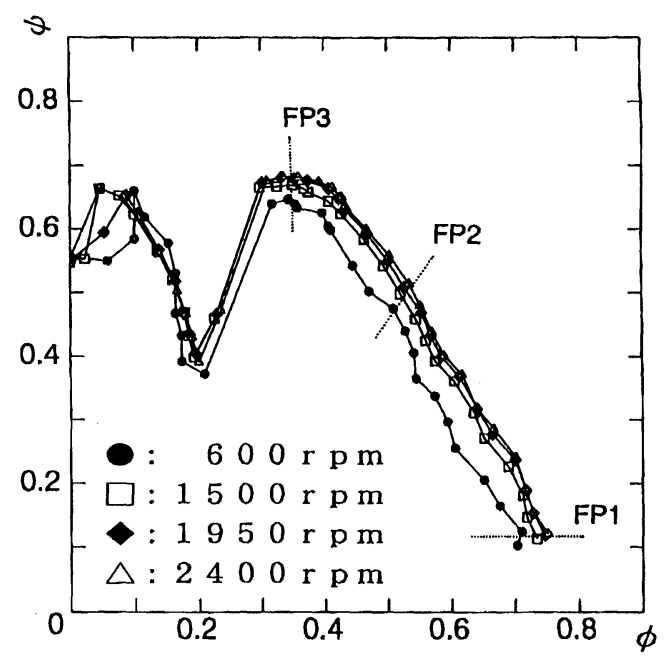

FIGURE 4 Operating conditions for measurement.
$2400 \mathrm{rpm}$. They were in the representative flow range in the laminar, transitional and their boundary operating conditions respectively.

\section{STEADY VELOCITY DISTRIBUTIONS IN THE FAN}

\subsection{Relative Velocity Distributions in the Down Stream of the Moving Blade}

Figures 5a,b show relative velocity distributions in the $\mathrm{Z}-\Theta$ plane. In these figures, the values are divided by the average values of the velocity component in the $\mathrm{Z}$-direction. The minimum points of the velocity component in the Z-direction are shown by $\circ$ markers and the dotted lines indicate the trailing edge of the blade. The domains of the wake shift to the suction side of the blade in the neighborhood of the hub. These domains

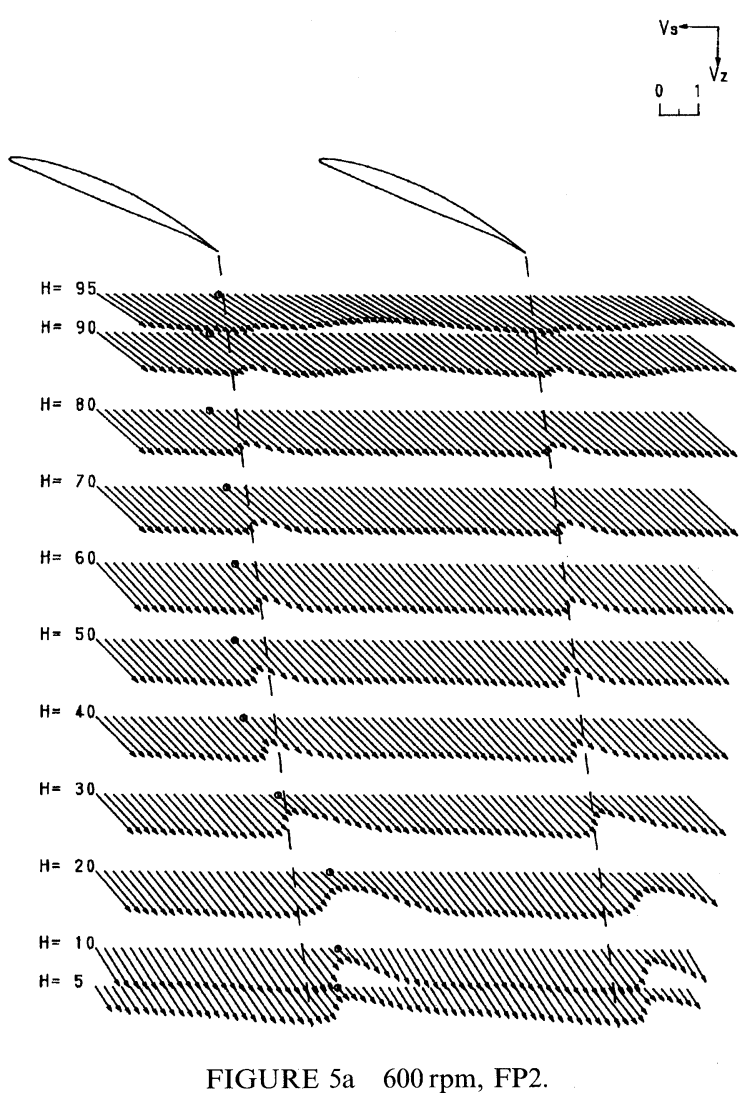




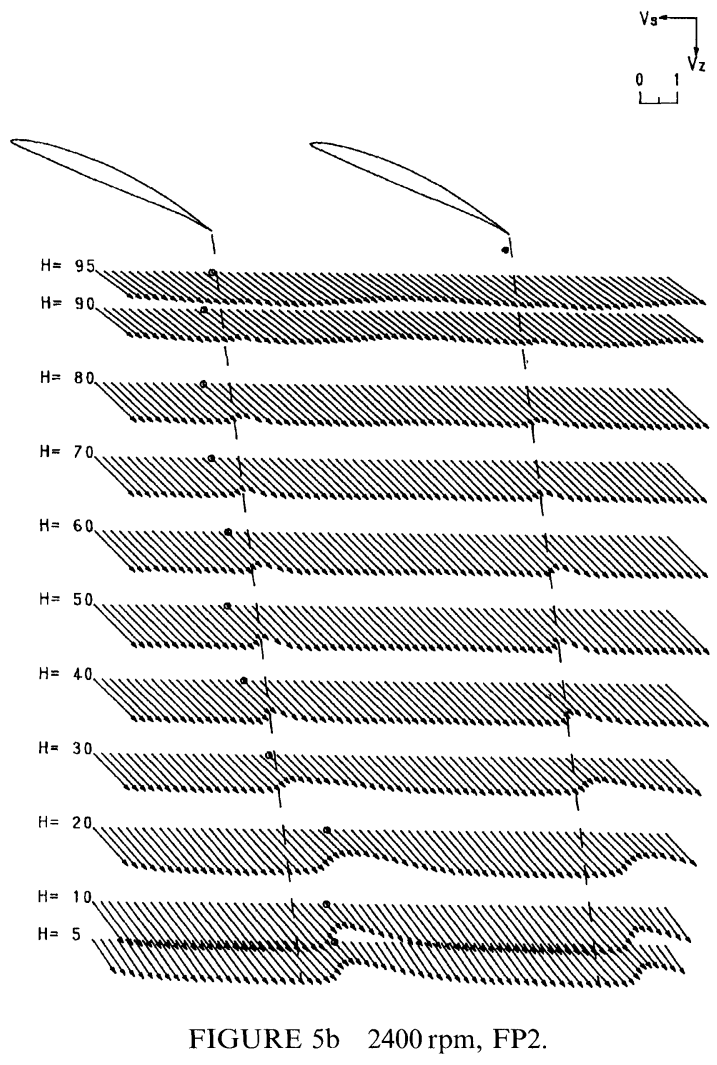

FIGURE 5 Relative velocity distribution in the downstream of moving blade.

become larger with a decrease in the discharge and in the neighborhood of the hub. They become larger with a decrease in rotational speed.

\subsection{Turning Angle of the Moving Blade Row}

By subtracting the relative inlet angle from the relative outlet angle, the turning angle is acquired (Figs. 6a,b,c). The relative outlet angle increases with a decrease in the discharge, but the relative inlet angle increases more. In consequence, the turning angle increases with a decrease in discharge. In these figures the dotted lines show the turning angle at the design point. For the same discharge coefficient, the turning angle increases with an increase in the rotational speed for rotational speeds of more than $1500 \mathrm{rpm}$. This shows the effect of Reynolds number.

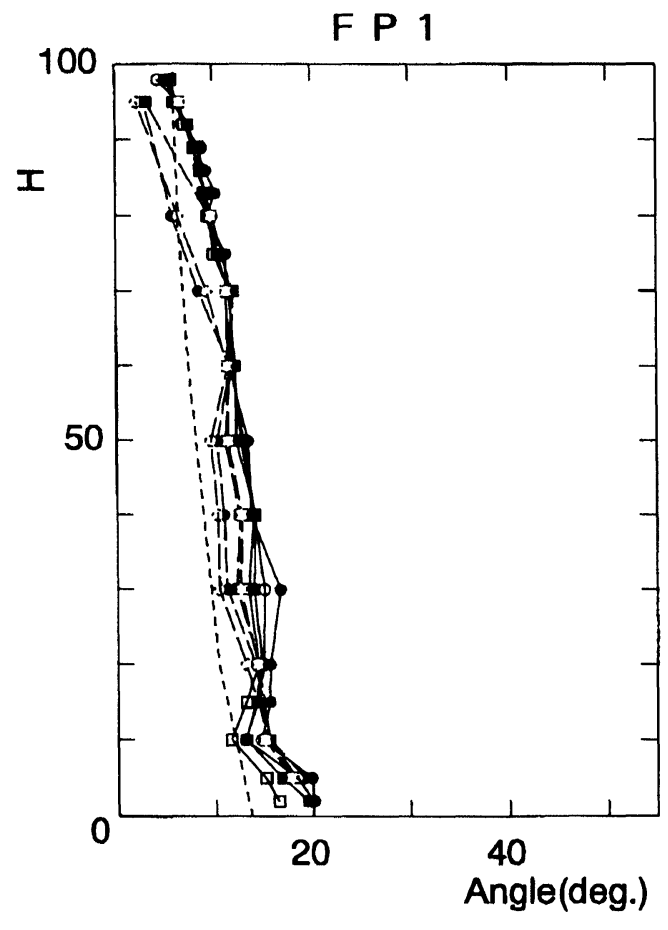

FIGURE 6a

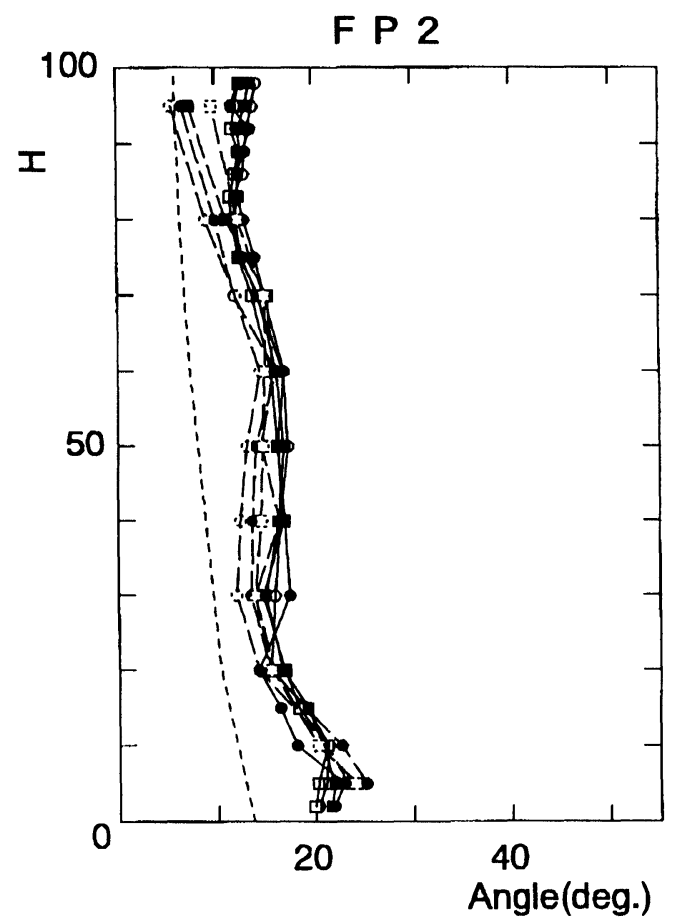

FIGURE 6b 


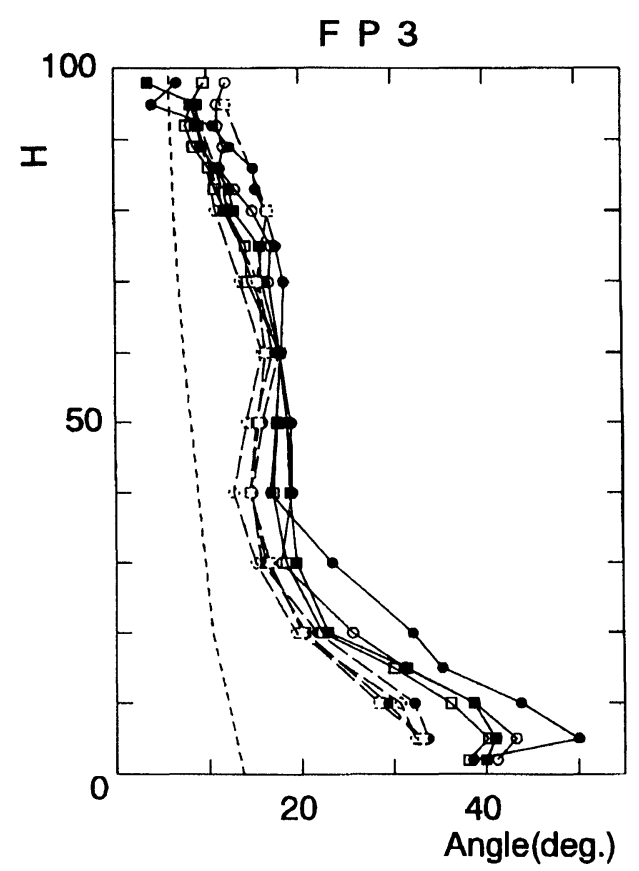

FIGURE 60

FIGURE 6 Turning angle of moving blade row.

\subsection{Velocity Distributions in the Blade Passage}

\section{a) Midway between the Tip and Hub}

Figures $7 \mathrm{a}, \mathrm{b}, \mathrm{c}$ shows velocity distributions in the moving blade passage. In these figures, arrows show velocity vectors on the circumferential surface and $\bullet$ markers show velocity components in the radial direction, taking outward as upward from the measuring points. In these figures, values are divided by the average value of the velocity components in the axial-direction. Velocity becomes larger from the pressure to the suction side. It is coincident with the calculated results using the cascade theory. The region of wake becomes larger from operating conditions FP1 to FP3. With an increase in the rotational velocity the flow phenomena become close to the potential flow.

\section{b) Near the $\mathrm{Hub}$}

In the neighborhood of the hub, boundary layers becomes thicker as shown in the Fig. 8a. These

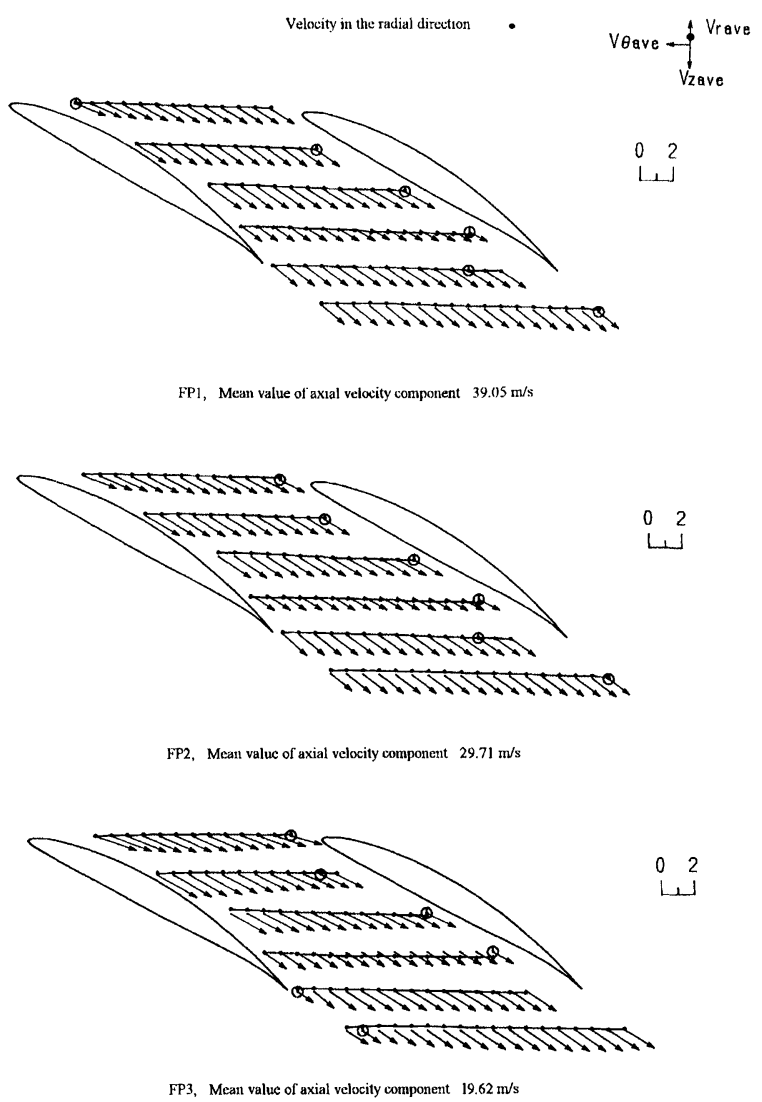

FIGURE 7 Velocity distributions in the blade row passage (1500 rpm, $\mathrm{H}=50$ ).

phenomena are clearer at the smaller rotational speeds.

\section{c) Near the Tip}

In the neighborhood of the tip, a radial outward flow can be seen near the suction surface and inward flow some distance apart. The velocity is larger near the suction surface. This shows the effect of leakage through tip clearance. Therefore the magnitude of the velocity becomes smaller near the midway point. Leakage becomes larger with an increase in pressure difference, as an effect. With an increase in the rotational speeds, the equalization effects of velocity can also be seen (Fig. 8b). 


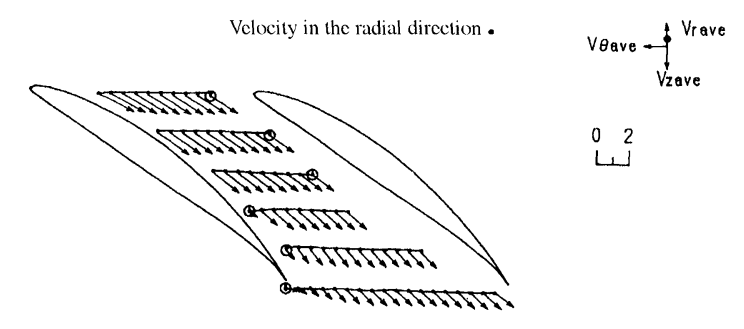

a. $\mathrm{H}=05$, Mcan valuc of axial velocity component $29.71 \mathrm{~m} / \mathrm{s}$

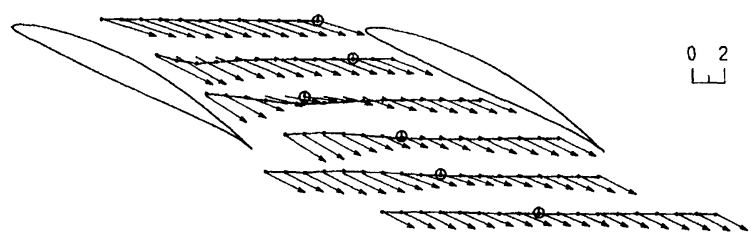

b. $\mathrm{H}=95$, Mcan value of axial velocity component $29.71 \mathrm{~m} / \mathrm{s}$

FIGURE 8 Velocity distributions in the blade row passage (1500 rpm, FP2).

\section{UNSTEADY VELOCITY DISTRIBUTIONS IN THE BLADE PASSAGE}

\subsection{Method of Expression of Unsteady Velocity}

At first, time averaged value of velocity at any point was calculated. They are designated by $V_{\text {Rave, }}$, $V_{\text {tave }}$ and $V_{\text {zave }}$. Unsteady velocity components at a measuring point and at any instant of relative position of stationary and moving blade rows are

$$
\begin{aligned}
V_{R}-V_{\text {Rave }} & =V_{\text {Rvar }} \\
V_{\theta}-V_{\theta a v e} & =V_{\theta v a r} \\
V_{Z}-V_{\text {Zave }} & =V_{Z v a r} .
\end{aligned}
$$

\subsection{Unsteady Velocity Component the Moving Blade Passage in the $\theta-Z$ Plane}

Figures 9a,b,c show unsteady velocity components in the moving blade passage in the $\theta-Z$ plane. They show the unsteady velocity distributions in the progress of time. In these figures arrows show unsteady velocity components in the $\theta-Z$ plane and - markers show those in the radial direction, positive in the upward direction from the measuring point. The mean flow are also shown in these figures. $\circ$ markers show the position of the minimum axial-velocity. These points correspond to the wake center.

\section{a) Midway between Tip and $\mathrm{Hub}$}

In this plane, unsteady components are small and wake flows regularly between the blade passage.

\section{b) Near the $\mathrm{Hub}$}

In this plane, the chord of the moving blade is larger and blade pitches become shorter. Then wakes are clearly seen. The radial components in the wake is somewhat larger and directed outward.

\section{c) Near the Tip}

In this plane, leakage from the tip clearance arises. Interference of leakage flow and wake of preceding stationary blade arise. Because of the interactions of leakage flow and wake of the stationary blade, an irregular unsteady flow arises.

\section{CONCLUSIONS}

In this paper, three dimensional steady and unsteady velocities were measured using a $45^{\circ}$ inclined hot wire probe. Flow phenomena in the blade passage were shown. Changes of the flow phenomena with a change of operational conditions and rotational speeds are shown. From these measurements the following conclusions have been acquired for the flow in the blade passage.

\section{Steady Velocity Distributions}

The domains of the wake shift to the suction side of the blade in the neighborhood of the hub. These domains become larger with a decrease in the discharge and also for the faster rotational speed. With an increase in the rotational speed turning angle of the blade increase. 


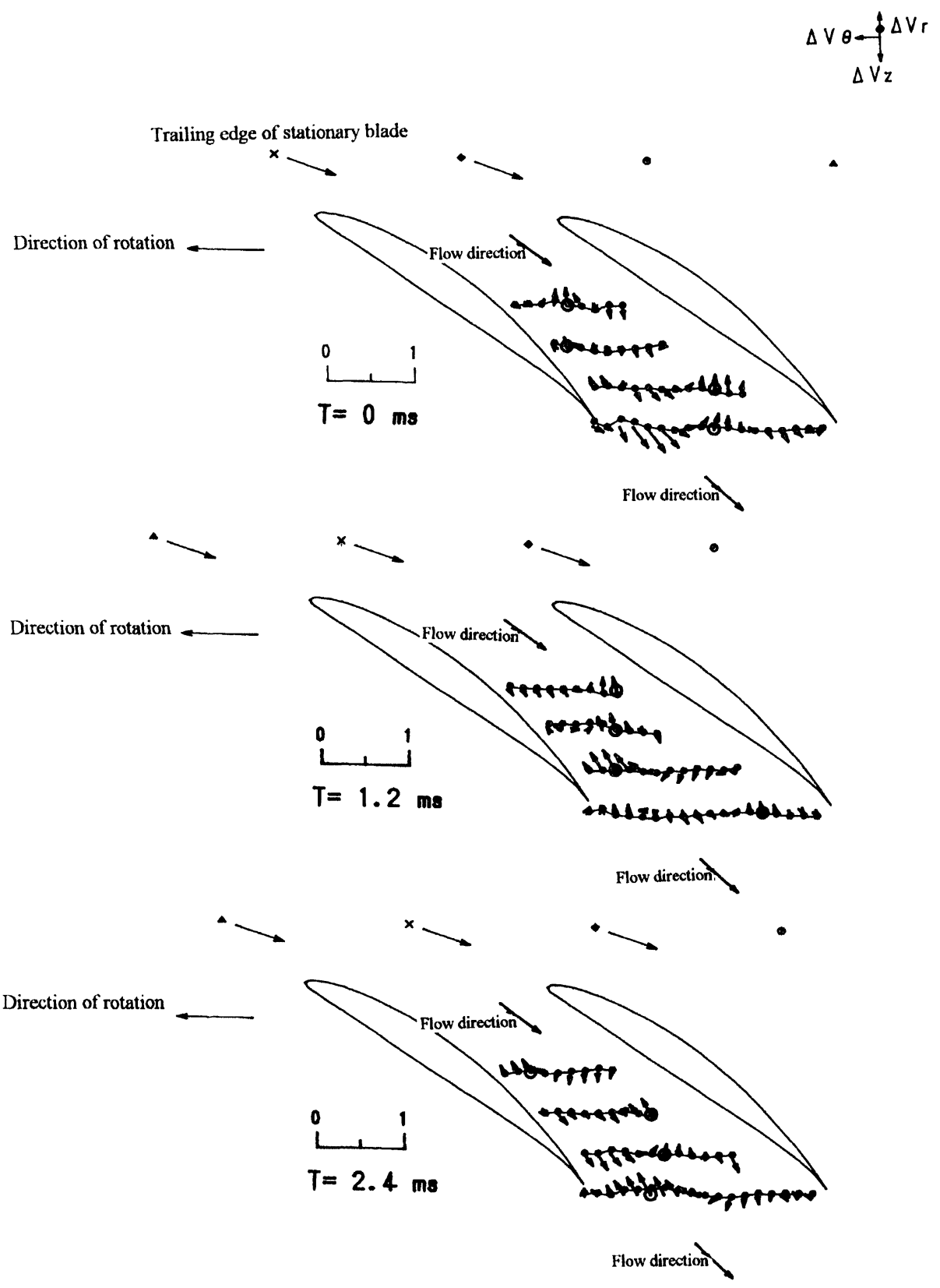

Mean value of axial velocity component $19.27 \mathrm{~m} / \mathrm{s}$

Mean value of outlet angle of stationary blade row relative to moving blade row $71.6^{\circ}$

Mean value of relative outlet angle of moving blade row $47.8^{\circ}$

FIGURE 9 Unsteady velocity distribution in the $\theta$-Z plane in the progress of time $(1500 \mathrm{rpm}, \mathrm{FP} 2, \mathrm{H}=05)$. 


\section{Unsteady Velocity Distributions}

Wakes are clearly seen and radial velocity components in the wake are somewhat larger and directed outward in the neighborhood of the hub. Interference of leakage flow and wake of preceding stationary blade can be seen near the tip. An unsteady irregular flow arises. Wake surfaces of the stationary blade can be seen comparatively remarkable. Radial outward flow can be recognized through the wake surface. With an increase in the rotational speed the mixing of the flow becomes remarkable. Intense irregularity of the wake surface becomes more and more remarkable with an increase in the rotational speed.

\section{References}

Adachi, T., Hino, T., Yamashita, Y., Kawai, T. and Matsuuchi, K. (1994). Measurement of the Three-Dimensional Flow in the Moving Blade Row of the Axial-Flow Blower, Proc. of the 4th Trinnial International Symposium on Fluid Control, Fluid Measurement, and Visualization, Touluse, 1001-1007. Adachi, T. Tomisawa, M., Hino, T., Yamashita, Y., Kawai, T. and Matsuuchi, K. Study on the Characteristics and the Flow in the Axial-Flow Fan (Effect of Reynolds Number), Turbomachinery, Vol. 23, No. 1 (in Japanese), 339-347. 


\section{ait \\ ENERGY MATERIALS}

M A N E Y publishing

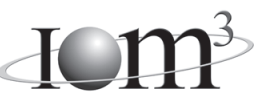

\section{Materials Science \& Engineering for Energy Systems}

Maney Publishing on behalf of the Institute of Materials, Minerals and Mining

The Institute of Materials, Minerals \& Mining

Economic and environmental factors are creating ever greater pressures for the efficient generation, transmission and use of energy. Materials developments are crucial to progress in all these areas: to innovation in design; to extending lifetime and maintenance intervals; and to successful operation in more demanding environments. Drawing together the broad community with interests in these areas, Energy Materials addresses materials needs in future energy generation, transmission, utilisation, conservation and storage. The journal covers thermal generation and gas turbines; renewable power (wind, wave, tidal, hydro, solar and geothermal); fuel cells (low and high temperature); materials issues relevant to biomass and biotechnology; nuclear power generation (fission and fusion); hydrogen generation and storage in the context of the 'hydrogen economy'; and the transmission and storage of the energy produced.

As well as publishing high-quality peer-reviewed research, Energy Materials promotes discussion of issues common to all sectors, through commissioned reviews and commentaries. The journal includes coverage of energy economics and policy, and broader social issues, since the political and legislative context influence research and investment decisions.

\section{CALL FOR PAPERS}

Contributions to the journal should be submitted online at http://ema.edmgr.com

To view the Notes for Contributors please visit: www.maney.co.uk/journals/notes/ema

Upon publication in 2006, this journal will be available via the Ingenta Connect journals service. To view free sample content online visit: www.ingentaconnect.com/content/maney

For further information please contact:

Maney Publishing UK

Tel: +44 (0)113 2497481 Fax: +44 (0)1132486983 Email: subscriptions@maney.co.uk

or

Maney Publishing North America

Tel (toll free): 8662975154 Fax: 6173546875 Email: maney@maneyusa.com

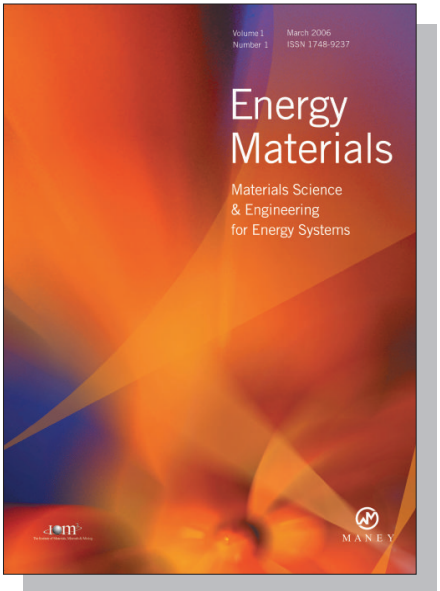

EDITORS

Dr Fujio Abe

NIMS, Japan

Dr John Hald, IPL-MPT, Technical University of Denmark, Denmark

Dr R Viswanathan, EPRI, USA

\section{SUBSCRIPTION INFORMATION}

Volume 1 (2006), 4 issues per year

Print ISSN: 1748-9237 Online ISSN: 1748-9245

Individual rate: $£ 76.00 / U S \$ 141.00$

Institutional rate: $£ 235.00 /$ US $\$ 435.00$

Online-only institutional rate: $£ 199.00 / U S \$ 367.00$

For special $\mathrm{IOM}^{3}$ member rates please email

subscriptions@maney.co.uk

\section{For further information or to subscribe online please visit www.maney.co.uk}



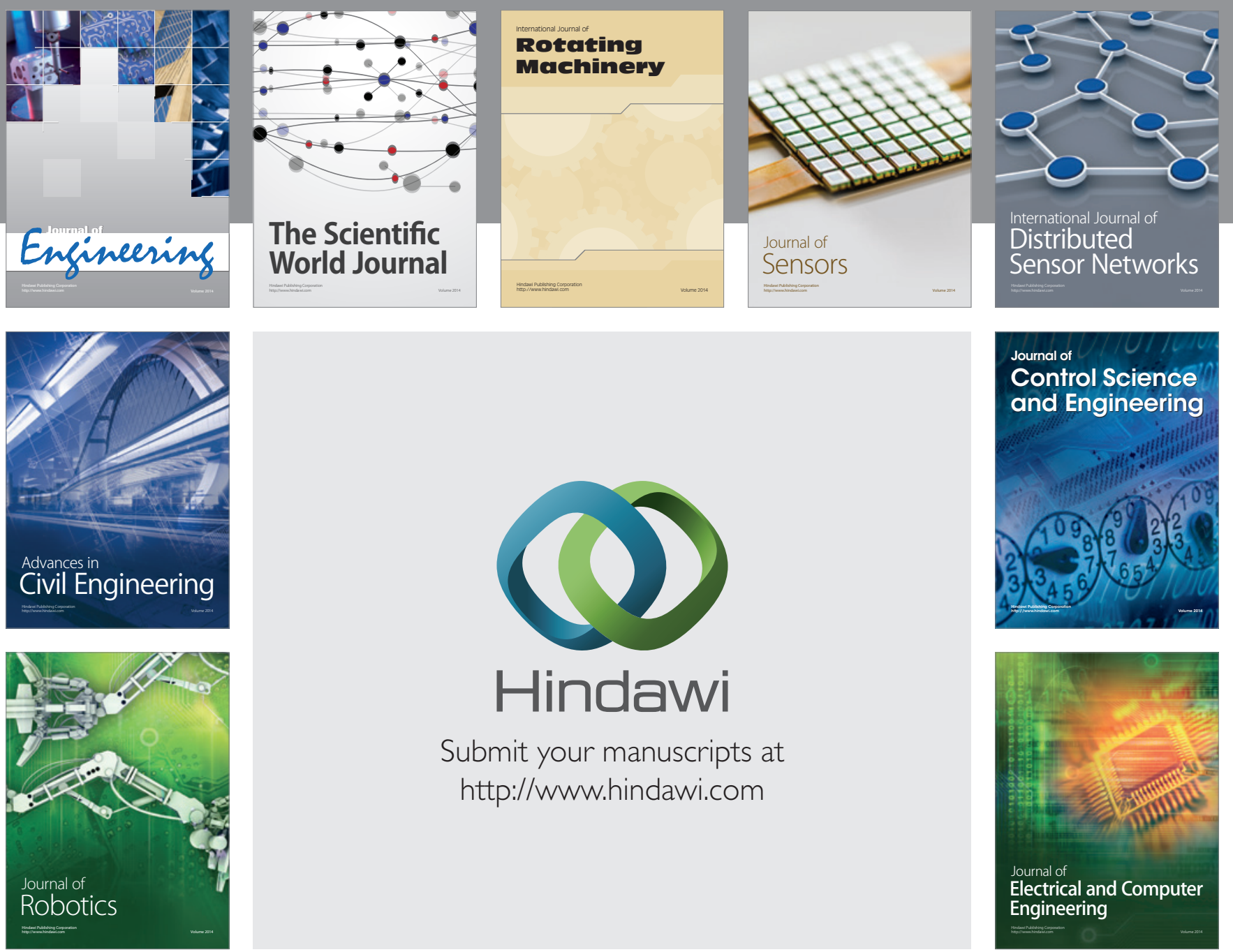

Submit your manuscripts at

http://www.hindawi.com
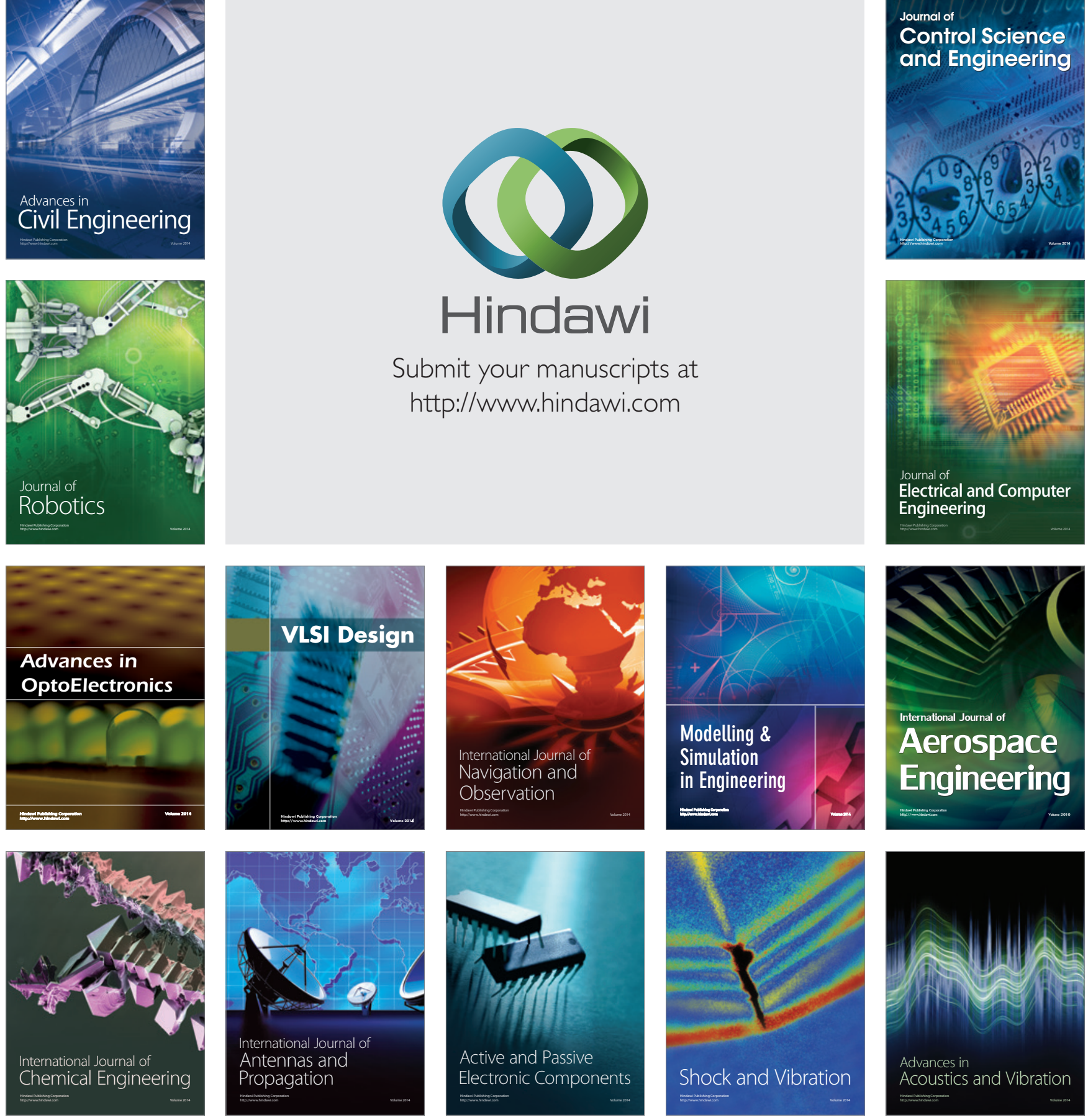